\title{
Photocatalytic hydrogen generation over alkali niobates in the presence of organic compounds
}

\author{
${ }^{1}$ Beata Zielińska, Joanna Sreńscek-Nazzal, Ryszard J. Kaleńczuk \\ Szczecin University of Technology,Institute of Chemical and Environment Engineering, ul. Pułaskiego 10, \\ 70-322 Szczecin, Poland \\ ${ }^{1}$ e-mail: bzielinska@ps.pl
}

\begin{abstract}
The photocatalytic efficiency of alkali niobate-based compounds ( $\mathrm{Li}, \mathrm{Na}, \mathrm{K})$ for hydrogen generation has been investigated. The systematic study showed that the highest photocatalytic activity was observed in the case of $\mathrm{Na} / \mathrm{Nb}_{2} \mathrm{O}_{5}$ catalyst which contained sodium niobate $\left(\mathrm{NaNbO}_{3}\right)$ phase and that the most efficient electron donor for hydrogen generation was formic acid. In addition, the effect of organic donor $(\mathrm{HCOOH})$ concentration on the amount of the evolved hydrogen was studied.
\end{abstract}

Keywords: Hydrogen generation, alkali niobates, photocatalysis.

\section{INTRODUCTION}

Heterogeneous photocatalysis is one of the technologies used for the removal of organic and inorganic contaminants and hydrogen generation ${ }^{1-5}$. However, photocatalysis is still in the development stage, and several aspects of this technology have yet to be explored. In the case of photocatalytic hydrogen generation, the low hydrogen production efficiency has limited the commercial application of this process. In order to improve the efficiency of the photocatalytic hydrogen generation it is necessary to add electron donors to the reaction system ${ }^{6-8}$. Those compounds are hole scavengers and undergo irreversible oxidation that results in the enhancement of photocatalytic hydrogen production. Many organic compounds in wastewater are very efficient electron donors and can be used as donors for photocatalytic hydrogen generation. It is very important to combine the photocatalytic generation of hydrogen with a simultaneous degradation of pollutants.

Therefore, nowadays many researchers conduct very intensive studies exploring the new types of the photocatalysts. One of the promising compounds is the material, such as niobate or tantalate. The reason for the investigation of these groups of compounds is that their flat band potentials are higher than those of titanates?.

In the current study, the efficiency of alkali niobate-based compounds used as photocatalysts in the reaction of photocatalytic hydrogen generation will be presented. Among the studied catalysts, the highest photocatalytic activity was observed for $\mathrm{Na} / \mathrm{Nb}_{2} \mathrm{O}_{5}$. The effect of the kind of organic compounds and the influence of formic acid concentration on the amount of the released hydrogen was present as well.

\section{EXPERIMENTAL}

High-purity grade niobium pentaoxide $\left(\mathrm{Nb}_{2} \mathrm{O}_{5}\right.$, purity $99.99 \%)$ and alkali hydroxides $\left(\mathrm{LiOH} \cdot \mathrm{H}_{2} \mathrm{O}, \mathrm{NaOH}\right.$ and $\mathrm{KOH}$ ) were used as the precursors for the preparation of modified photocatalysts. In the first step of the photocatalysts preparation $\mathrm{Nb}_{2} \mathrm{O}_{5}$ was impregnated in the aqueous solutions of alkali metals. The molar ratio of $\mathrm{Me} / \mathrm{Nb}_{2} \mathrm{O}_{5}$ (Memetals) was 2:1. After impregnation the as-obtained materials were dried at the temperature of $110^{\circ} \mathrm{C}$ for $24 \mathrm{~h}$ and then calcinated at the temperature of $550^{\circ} \mathrm{C}$. The annealing time at the required calcination temperature was fixed for 11 hours. Afterwards, the obtained materials were ground in a ceramic mortar, forming a fine powder. In the next step, the fine powder was washed with distilled water until neutral $\mathrm{pH}$ was reached. The samples obtained after water treating were dried at the temperature of $110^{\circ} \mathrm{C}$ for 24 hours and labeled as follows: $\mathrm{Me} / \mathrm{Nb}_{2} \mathrm{O}_{5}(\mathrm{Me}=\mathrm{Li}, \mathrm{Na}, \mathrm{K})$.

The activities of the obtained catalysts for hydrogen generation in the presence of organic compounds, such as formic acid, acetic acid, formaldehyde, methanol and 2-propanol in a close system with inner-irradiation-type reactor, were examined. As a light source a medium pressure mercury lamp of $150 \mathrm{~W}$ was applied. This lamp provided the light of the wavelength ranging from $200 \mathrm{~nm}$ to $600 \mathrm{~nm}$ with the maximum intensity of $366 \mathrm{~nm}$. In the beginning, the photocatalyst powders were dispersed in an aqueous solution of organic donor $\left(0.8 \mathrm{dm}^{3}\right)$. Afterwards, the suspension was mixed with the magnetic stirrer for 1 hour, and during that time argon was bubbling through the reaction mixture to remove oxygen content. Later, the solution was irradiated without argon purge. The amount of the evolved hydrogen was determined using a gas chromatograph (The Thermal Conductivity Detector (TCD), Ar as a gas carrier).

\section{RESULTS AND DISCUSSION}

In the first step, we examined the photocatalytic hydrogen generation over all the produced photocatalysts $\left(\mathrm{Li} / \mathrm{Nb}_{2} \mathrm{O}_{5}\right.$, $\mathrm{Na} / \mathrm{Nb}_{2} \mathrm{O}_{5}$ and $\mathrm{K} / \mathrm{Nb}_{2} \mathrm{O}_{5}$ ) using formic acid as a model organic electron donor. The reactions were conducted with $\mathrm{HCOOH}$ concentration of $1000 \mathrm{mmol} / \mathrm{dm}^{3}$ and a constant amount of the photocatalyst $(0.2 \mathrm{~g})$. The comparison of hydrogen evolution over the studied photocatalysts is presented in Fig. 1. The kinetics of hydrogen generation in the presence of formic acid during the first 6 hours of UV irradiation can be described by zero order kinetics. The rate constants of hydrogen evolution are about 30.7, 40.8 and $27.4 \mu \mathrm{mol} / \mathrm{h}$ for $\mathrm{Li} / \mathrm{Nb}_{2} \mathrm{O}_{5}, \mathrm{Na} / \mathrm{Nb}_{2} \mathrm{O}_{5}$ and $\mathrm{K} / \mathrm{Nb}_{2} \mathrm{O}_{5}$, respectively. It is clearly seen that the highest photocatalytic activity was observed in the case of $\mathrm{Na} / \mathrm{Nb}_{2} \mathrm{O}_{5}$ catalyst. Detailed characteristics (XRD, DR-UV-Vis, FTIR/DRS and BET) of those photocatalysts were given elsewhere ${ }^{10}$. On the basis of the previous investigation (data not shown here) one can notice that the photocatalysts obtained after the reaction of the $\mathrm{Nb}_{2} \mathrm{O}_{5}$ with the alkali hydroxides contained mixtures of alkali niobates and a small amount of niobium pentaoxide. 


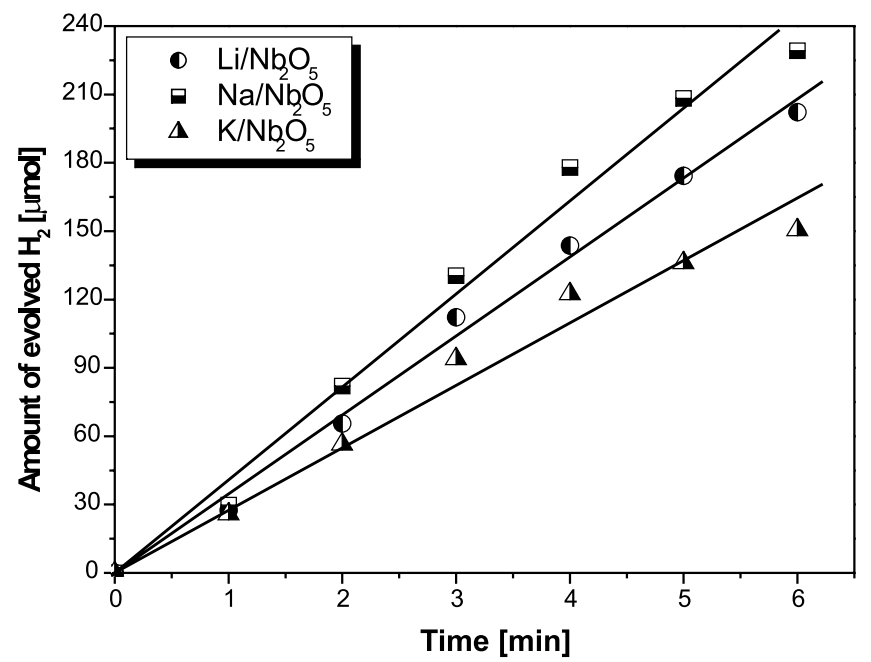

Figure 1. The photocatalytic $\mathrm{H}_{2}$ evolution over $\mathrm{Li} / \mathrm{Nb}_{2} \mathrm{O}_{5}$, $\mathrm{Na} / \mathrm{Nb}_{2} \mathrm{O}_{5}$ and $\mathrm{K} / \mathrm{Nb}_{2} \mathrm{O}_{5}$ photocatalysts $(\mathrm{HCOOH}$ concentration- $1000 \mathrm{mmol} / \mathrm{dm}^{3}$, amount of catalyst$0.2 \mathrm{~g})$

The alkali niobates have the hexagonal structure $\left(\mathrm{LiNbO}_{3}\right.$, $\mathrm{NaNbO}_{3}$ and $\mathrm{KNbO}_{3}$ ), which determines the main phase of the investigated samples. Additionally, we can state that the modification of $\mathrm{Nb}_{2} \mathrm{O}_{5}$ with alkali metals caused an increase of the BET surface areas of all the prepared samples. According to the manufacture' data, $\mathrm{Nb}_{2} \mathrm{O}_{5}$ has small specific surface area of $0.76 \mathrm{~m}^{2} / \mathrm{g}$. The BET surface area of $\mathrm{Li} /$ $\mathrm{Nb}_{2} \mathrm{O}_{5}, \mathrm{Na} / \mathrm{Nb}_{2} \mathrm{O}_{5}$ and $\mathrm{K} / \mathrm{Nb}_{2} \mathrm{O}_{5}$ are about $6\left(4.7 \mathrm{~m}^{2} / \mathrm{g}\right), 6.4$ $\left(4.84 \mathrm{~m}^{2} / \mathrm{g}\right)$ and $4\left(2.81 \mathrm{~m}^{2} / \mathrm{g}\right)$ times higher than that of the pristine $\mathrm{Nb}_{2} \mathrm{O}_{5}$, respectively. It indicated that the catalyst with the highest surface area $\left(\mathrm{Na} / \mathrm{Nb}_{2} \mathrm{O}_{5}, 4.84 \mathrm{~m}^{2} / \mathrm{g}\right)$ exhibited the highest photocatalytic activity.

Further experiments were conducted using the $\mathrm{Na} / \mathrm{Nb}_{2} \mathrm{O}_{5}$ catalyst (as the one with the highest photoactivity) in the presence of different kinds of organic donors such as formic acid, acetic acid, formaldehyde, methanol and 2-propanol. The results are shown in Fig. 2. From the obtained results it is clearly seen that formic acid is the most efficient electron donor for photocatalytic hydrogen generation. Additionally, one can notice that the kinetics of hydrogen generation in the presence of all the organic compounds during the first 6 hours of UV irradiation can be described by zero

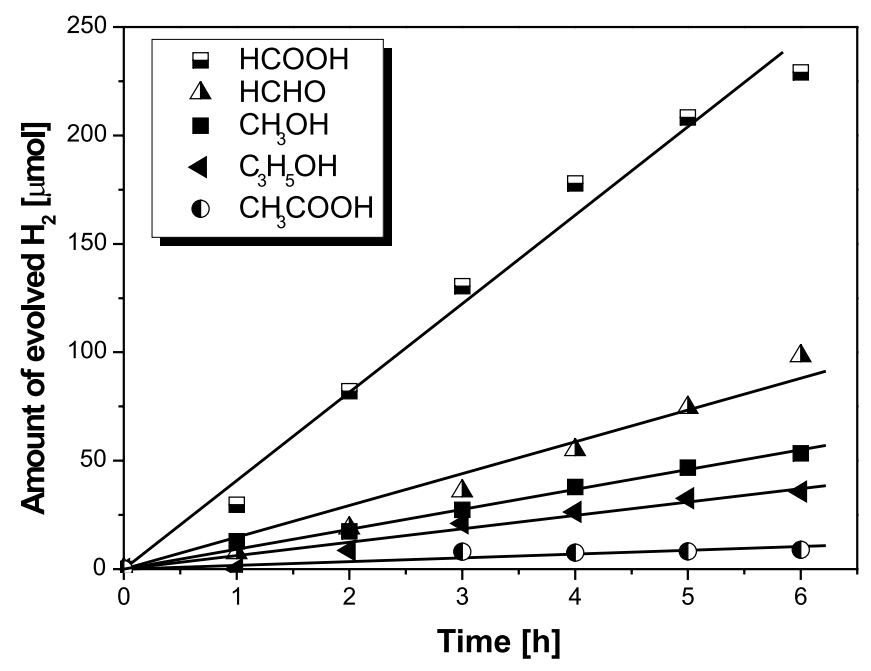

Figure 2. The photocatalytic hydrogen evolution over $\mathrm{Na}$ / $\mathrm{Nb}_{2} \mathrm{O}_{5}$ photocatalyst using different organic compounds (organic compound concentrations - 1000 $\mathrm{mmol} / \mathrm{dm}^{3}$ ) order kinetics. The rate constants of hydrogen evolution are: $40.8 \mu \mathrm{mol} / \mathrm{h}(\mathrm{HCOOH}), 14.67 \mu \mathrm{mol} / \mathrm{h}(\mathrm{HCHO}), 9.18 \mu \mathrm{mol} / \mathrm{h}$ $\left(\mathrm{CH}_{3} \mathrm{OH}\right), 6.18 \mu \mathrm{mol} / \mathrm{h}\left(\mathrm{C}_{3} \mathrm{H}_{5} \mathrm{OH}\right)$ and $1.73 \mu \mathrm{mol} / \mathrm{h}$ $\left(\mathrm{CH}_{3} \mathrm{COOH}\right)$. The amount of hydrogen obtained in the presence of $\mathrm{HCOOH}$ is about 3 and 25 times higher than that in the presence of $\mathrm{HCHO}$ and $\mathrm{CH}_{3} \mathrm{COOH}$, respectively. The explanation of the above-described results has been given elsewhere ${ }^{11}$.

Now we turn to the analysis of the dependence of the released hydrogen in the photocatalytic reaction in the presence of formic acid as an example organic donor. The study was conducted with the formic acid concentration ranging between 50 and $1000 \mathrm{mmol} / \mathrm{dm}^{3}$. The results are shown in Fig. 3. From this figure it is clearly seen that the amount of $\mathrm{H}_{2}$ released increases with the increasing of $\mathrm{HCOOH}$ concentration from $50 \mathrm{mmol} / \mathrm{dm}^{3}\left(\mathrm{H}_{2}-58.5 \mu \mathrm{mol} / \mathrm{h}\right)$ to 100 $\mu \mathrm{mol} / \mathrm{dm}^{3}\left(\mathrm{H}_{2}-73.76 \mu \mathrm{mol} / \mathrm{h}\right)$. Further increase of the $\mathrm{HCOOH}$ concentration to $1000 \mathrm{mmol} / \mathrm{dm}^{3}\left(\mathrm{H}_{2}-40.8 \mu \mathrm{mol} / \mathrm{h}\right)$ caused a decrease in the amount of hydrogen generated. The initial increase of hydrogen generation (from 50 to $100 \mathrm{mmol} /$ $\mathrm{dm}^{3}$ ) can be expected by the competition between water and formic acid with valence band holes $\left(\mathrm{h}^{+}\right)$. The water, which is present in the formic acid solution splits into hydroxyl radicals $\left(\mathrm{OH}^{*}\right)$ and $\mathrm{H}^{+}$ions through $\mathrm{H}_{2} \mathrm{O}$ oxidation. The obtained hydroxyl radicals generate oxygen while at the same time at the conduction band the excited electrons are withdrawn by $\mathrm{H}^{+}$ions resulting in the evolution of $\mathrm{H}_{2}$. It is worth pointing here that the presence of oxygen in the reaction system competes with photogenerated $\mathrm{H}^{+}$ions to react with the electrons in the conduction band to form $\mathrm{O}_{2}^{\circ-}$. On the other hand, the significant decrease of the released hydrogen (from 100 to $1000 \mathrm{mmol} / \mathrm{dm}^{3}$ ) can be explained by the increase of the absorption formic acid on $\mathrm{Na} / \mathrm{Nb}_{2} \mathrm{O}_{5}$ catalyst. High adsorption could cause the formation of several layers of adsorbed compounds on the photocatalyst surface, which inhibits the reaction of $\mathrm{H}^{+}$ions with photogenerated electrons. There would be no simple access of the $\mathrm{H}^{+}$to the electrons. Additionally, the high adsorption can cause the limited access of the UV light to the active sites of the catalyst surface. A detailed study to verify the proposed explanation is currently in progress ${ }^{12,13}$.

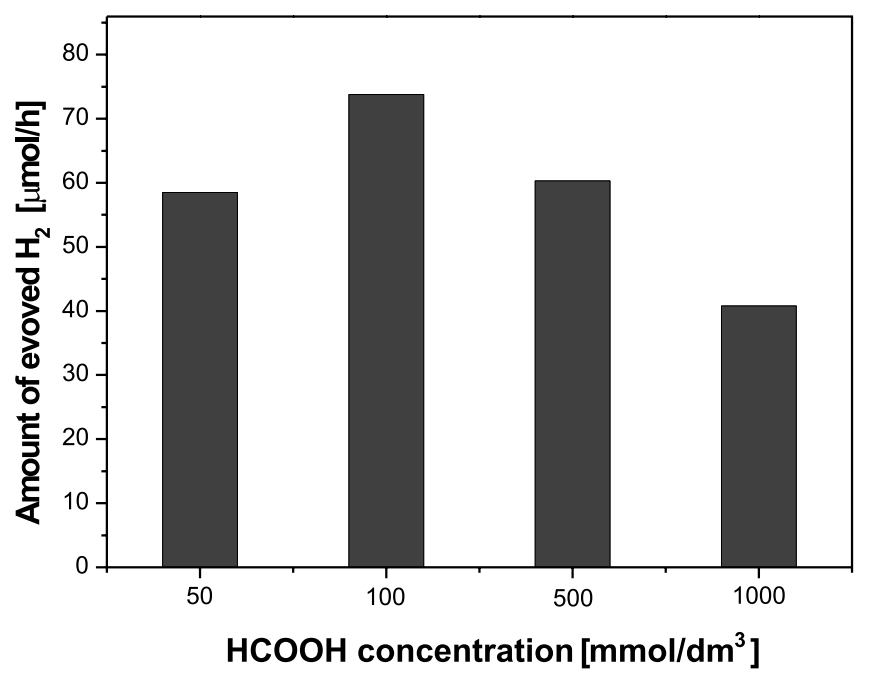

Figure 3. The effect of $\mathrm{HCOOH}$ concentration on the amount of evolved $\mathrm{H}_{2}$ in the presence of $\mathrm{Na} / \mathrm{Nb}_{2} \mathrm{O}_{5}$ 


\section{CONCLUSION}

In summary, three produced photocatalysts $\left(\mathrm{Li} / \mathrm{Nb}_{2} \mathrm{O}_{5}\right.$, $\mathrm{Na} / \mathrm{Nb}_{2} \mathrm{O}_{5}$ and $\mathrm{K} / \mathrm{Nb}_{2} \mathrm{O}_{5}$ ) have been tested in the reaction of photocatalytic hydrogen generation in the presence of different kinds of organic compounds $(\mathrm{HCOOH}$, $\mathrm{CH}_{3} \mathrm{COOH}, \mathrm{CH}_{3} \mathrm{OH}, \mathrm{C}_{3} \mathrm{H}_{5} \mathrm{OH}$ and $\mathrm{HCHO}$ ). To conclude, the highest photocatalytic activity was observed for the samples named with $\mathrm{Na} / \mathrm{Nb}_{2} \mathrm{O}_{5}$. Here, we prove that the formic acid was the most efficient organic compound for hydrogen generation. Additionally, the effect of organic donor $(\mathrm{HCOOH})$ concentration on the amount of evolved hydrogen was studied.

\section{ACKNOWLEDGMENTS}

This work was sponsored by Polish State Committee for Scientific Research grant N523 025 32/0983 (B.Z.).

\section{LITERATURE CITED}

1. Shon, H.K., Vigneswaran, S., Ngo, H.H., Kim, J.-H. \& Kandasamy, J. (2007). Effect of flocculation as a pretreatment to photocatalysis in the removal of organic matter from wastewater. Sep. Purif. Technol. 56, 388 - 391. DOI: 10.1016/j.seppur.2007.04.023.

2. Selli, E., Bianchi, C.L., Pirola, C., Cappelletti G. \& Ragaini, V. (2008). Efficiency of 1,4-dichlorobenzene degradation in water under photolysis, photocatalysis on $\mathrm{TiO}_{2}$ and sonolysis. J. Hazard. Mater. 153, 1136 - 1141. DOI: 10.1016/j.jhazmat.2007.09.071.

3. Ji, S.M., Jun, H., Jang, J.S., Son, H.Ch., Borse, P.H. \& Lee, J.S. (2007). Photocatalytic hydrogen production from natural seawater. J. Photochem. Photobiol. A. 189, 141 - 144. DOI: $10.1016 / \mathrm{j}$.jphotochem.2007.01.011.

4. Ikeda, M., Kusumoto, Y., Somekawa, S., Ngweniform, P. \& Ahmmad, B. (2006). Effect of graphite silica on $\mathrm{TiO}_{2}$ photocatalysis in hydrogen production from water-methanol solution. J. Photochem. Photobiol. A. 184, 306 - 312. DOI: 10.1016/j.jphotochem.2006.04.031.

5. Liu, Y., Guo, L., Yan, W., Liu, H., Liu, Y., Guoa, L., Yan, W. \& Liu, H. (2006). A composite visible-light photocatalyst for hydrogen production. J. Power Sources. 159, 1300 - 1304. DOI: 10.1016/j.jpowsour.2005.11.105.

6. Li, Y., Lu, G. \& Li, S. (2003). Photocatalytic production of hydrogen in single component and mixture systems of electron donors and monitoring adsorption of donors by in situ infrared spectroscopy. Chemosphere. 52, 843 - 850. DOI: 10.1016/S0045-6535(03)00297-2.

7. Li, Y., Xie, Y., Peng, S., Lu, G. \& Li, S. (2006). Photocatalytic hydrogen generation in the presence of chloroacetic acids over $\mathrm{Pt} / \mathrm{TiO}_{2}$. Chemosphere. 63, 1312 - 1318. DOI: 10.1016/j.chemosphere.2005.09.004.

8. Li, Y., Lu, G. \& Li, S. (2001). Photocatalytic hydrogen generation and decomposition of oxalic acid over platinized $\mathrm{TiO}_{2}$. Appl. Catal. A. 214, $179-185$.

9. Kato, H. \& Kudo, A. (1998). New tantalate photocatalysts for water decomposition into $\mathrm{H}_{2}$ and $\mathrm{O}_{2}$. Chem. Phys. Lett. $295,487-492$.

10. Zielińska, B., Arabczyk, A. \& Kaleńczuk R.J. (2007). Preparation of $\mathrm{Nb}_{2} \mathrm{O}_{5}$ photocatalysts by alkali metals ( $\mathrm{Li}, \mathrm{Na}$, $\mathrm{K})$ and its photocatalytic performance. Polish J. Chem. 81, 1355 - 1362 .

11. Zielińska, B., Borowiak-Palen, E. \& Kalenczuk, R.J. (2008). Photocatalytic hydrogen generation over alkalineearth titanates in the presence of electron donors. International J. Hydrogen Energy. 33, 1797 - 1802. DOI: 10.1016/ j.ijhydene.2008.02.00.1
12. Zielińska, B., Borowiak-Palen, E. \& Kalenczuk, R.J. (2008). Preparation and characterization of lithium niobate as a novel photocatalyst in hydrogen generation. J. Phys. Chem. Solid. 69, 236 - 242. DOI: 10.1016/j.jpcs.2007.09.001.

13. Gondal, M.A., Hameed, A. \& Yamani, Z.H. (2004). Hydrogen generation by laser transformation of methanol using n-type $\mathrm{WO}_{3}$ semiconductor catalyst. J. Mol. Catal. A. 222, 259 - 264. DOI: 10.1016/j.molcata.2004.08.022. 